American Journal of Pharmaceutical Education 2019; 83 (2) Article 6867.

\title{
BRIEF
}

\section{A Study of the Relationship Between the PCOA and NAPLEX Using a Multi-institutional Sample}

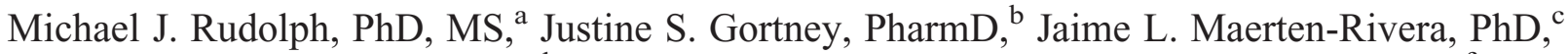 \\ Brenda S. Bray, MPH, BPharm, ${ }^{\mathrm{d}}$ Sachin Shah, PharmD, ${ }^{\mathrm{e}}$ Bradley E. Hein, PharmD, BS, ${ }^{\mathrm{f}}$ \\ Elizabeth A. Coyle, PharmD, ${ }^{g}$ Shauna M. Buring, PharmD ${ }^{\mathrm{h}}$ \\ ${ }^{a}$ University of Kentucky, Lexington, Kentucky \\ ${ }^{\mathrm{b}}$ Wayne State University Eugene Applebaum College of Pharmacy and Health Sciences, Detroit, Michigan \\ ${ }^{c}$ State University of New York at Buffalo School of Pharmacy and Pharmaceutical Sciences, Buffalo, New York \\ ${ }^{\mathrm{d}}$ Washington State University Elson S. Floyd College of Medicine, Spokane, Washington \\ e Texas Tech University Health Sciences Center, Lubbock, Texas \\ ${ }^{\mathrm{f}}$ University of Cincinnati James L. Winkle College of Pharmacy, Cincinnati, Ohio \\ ${ }^{\mathrm{g}}$ University of Houston College of Pharmacy, Houston, Texas \\ ${ }^{\mathrm{h}}$ University of Florida College of Pharmacy, Gainesville, Florida
}

Submitted November 2, 2017; accepted June 29, 2018; published March 2019.

Objective. To examine the relationship between the Pharmacy Curriculum Outcomes Assessment (PCOA) and the North American Pharmacist Licensure Examination (NAPLEX) using a large, multi-institutional sample of student scores.

Methods. A matched dataset was obtained from the National Association of Boards of Pharmacy (NABP) consisting of examination scores for the 1,460 students who completed both the PCOA and the NAPLEX between 2012 and 2015 at six schools/colleges of pharmacy (S/COPs). Bivariate correlations were estimated for total and content area scores on both examinations. Students' total NAPLEX scores were predicted using linear regression models containing total and content area scores on PCOA and dummy variables for S/COP and year.

Results. Students' PCOA total score and NAPLEX total score were significantly and moderately correlated $(r=0.54)$. All correlations between PCOA and NAPLEX total and content area scores were significant. and ranged from $r=0.22$ to 0.56 . Regression results showed pharmaceutical and clinical sciences PCOA content scores were significant predictors of NAPLEX total score while basic biomedical sciences and social/behavioral/administrative sciences were not. The PCOA total and content scores accounted for $30 \%-33 \%$ of the variance in total NAPLEX score.

Conclusion. Student PCOA and NAPLEX total and content area scores were significantly correlated, which is consistent with the findings of previous research. The somewhat modest proportion of variance in NAPLEX scores accounted for by PCOA scores illustrates the need for use of additional performance measures when evaluating student preparedness for the NAPLEX. This study provides important baseline data that can be used by S/COPs for comparison with their own student data as well as by researchers seeking to conduct additional analyses following recent changes in the PCOA and NAPLEX blueprints.

Keywords: Pharmacy Curriculum Outcomes Assessment (PCOA), North American Pharmacist Licensure Examination (NAPLEX), assessment, predictors of student performance

Corresponding Author: Michael J. Rudolph, Office of Strategic Planning \& Institutional Effectiveness, 549 Patterson Office Tower, University of Kentucky, Lexington, KY 40506. Tel: 859-257-4945. E-mail: rudolph@uky.edu Note: At the time of the study, Dr. Rudolph was affiliated with the Marshall University School of Pharmacy.

\section{INTRODUCTION}

The Pharmacy Curriculum Outcomes Assessment (PCOA) is a validated, standardized examination developed by the National Association of Boards of Pharmacy (NABP) in 2008 to assess student performance within the doctor of pharmacy (PharmD) curriculum. ${ }^{1}$ The blueprint for the examination was based upon a NABP survey administered periodically to all US schools and colleges of 


\section{American Journal of Pharmaceutical Education 2019; 83 (2) Article 6867.}

pharmacy (S/COPs) to determine curricular coverage in key content and topic areas. ${ }^{2}$ The PCOA contains four major content areas: the basic biomedical sciences (BBS), pharmaceutical sciences (PS), social/behavioral/administrative pharmacy sciences (SBS), and clinical sciences (CS). ${ }^{1}$ In addition to providing a measure of individual student performance, the institutional score reports indicate the performance of specific student cohorts within a S/COP relative to a national sample. In this way, the PCOA has the potential to serve as one element within a S/COP's curricular assessment plan.

The PCOA possesses certain similarities and differences with another major standardized examination, the North American Pharmacy Licensing Examination (NAPLEX). ${ }^{3}$ Selected parts of the PCOA blueprint closely resemble the NAPLEX, although the domains do not map directly to one another. ${ }^{2}$ While both examinations focus heavily upon pharmaceutical and clinical sciences, approximately $32 \%$ of the items on the PCOA address the BBS and SBS, which receive limited attention on the NAPLEX. Scoring is also very different because of the nature of the examinations. ${ }^{4}$ Overall and domain-level PCOA scaled scores range from 0-700, whereas overall NAPLEX scores range from 0150, with a pass/fail cut score of $75 .{ }^{3,4}$ Lastly, the stakes and purposes of the two examinations are different in that the PCOA is often used as a low-stakes, knowledgebased assessment, whereas the NAPLEX is a highstakes assessment for all students and designed to assess competency. ${ }^{2}$

Adoption of the PCOA was somewhat limited prior to recent changes in the accreditation requirements, despite the potential of the examination as an important student and curricular assessment. ${ }^{5}$ The Accreditation Council for Pharmacy Education (ACPE) 2016 Standards emphasize the PharmD program's role in ensuring student success in the profession, including use of outcome data from assessments of student preparedness to progress to Advanced Pharmacy Practice Experiences. ${ }^{6}$ Moreover, in the Guidance for Standards 2016, the PCOA is specifically identified as a "valid and reliable assessment of student competence in the four broad sciences domains of the didactic curriculum" and students' PCOA scores are listed as part of the required documentation for a program's self-study. ${ }^{7,8}$ In response to ACPE's mandate to include outcome measures such as PCOA performance and to identify means of supporting student success, it is logical for PharmD educators to seek to understand the relationship between the PCOA and the NAPLEX. Determination of predictors of success (or failure) on the NAPLEX enables programs to identify students who are potentially at risk and customize or modify their education in order to increase their likelihood of success.

To date, a handful of studies have evaluated the relationship between student PCOA and NAPLEX scores. One study that used a sample of students who completed the PCOA in 2012 or 2013 at a single college of pharmacy found a moderate and significant relationship between the total scaled scores on the two examinations $(r=0.61$ to $r=0.73) .{ }^{9}$ Another study by Sousa et al used a sample drawn from two cohorts at one S/COP $(n=105)$ to estimate the correlations between the PS and CS content area scores of the PCOA and total NAPLEX scores. ${ }^{10}$ All correlations were significant and ranged in magnitude from $r=0.49$ to $r=0.57$. The strongest correlation was observed between a combined measure of the pharmaceutical sciences and clinical sciences content scores on the PCOA and the NAPLEX total score. Using multiple linear regression, they also demonstrated that $33 \%$ of the variation in NAPLEX scores could be explained by student PCOA scores.

A 2014 study by Naughton and Friesner provides the most detailed information to date on the relationship between the PCOA and NAPLEX. ${ }^{11}$ Using a sample of 172 students from one S/COP, their study determined that all PCOA and NAPLEX area scores were significantly correlated with one exception: SBS PCOA scores did not correlate with NAPLEX area 2 scores (assess safe and accurate methods to prepare and dispense medications). The magnitude of the PCOA total score and NAPLEX total score correlation was moderate $(r=0.59)$, and the correlations between PCOA and NAPLEX content areas ranged from $r=0.17$ to $r=0.58$. These findings led the authors to conclude the PCOA could provide formative assessment data to correct possible student deficiencies prior to graduation.

Published studies regarding the correlation between students' PCOA and NAPLEX scores have a number of limitations. First, they have generally used small samples with less than 400 cases, and often less than 200 cases, and power calculations were not reported. Second, such studies have typically drawn a convenience sample from a single institution and used limited institution data sets obtained through signed student authorization forms. Such reliance on students to release their scores to the S/COP may lead to biased sampling. Third, not all studies have examined the relationship between the content areas of the two examinations but instead focused only on total scores. This is a limitation as researchers have found in mapping and analysis of content area relationship that stronger relationships may exist between some domains than between others (eg, clinical sciences of PCOA were more relative to NAPLEX sections 1 and 2). ${ }^{10,11}$ In light 


\section{American Journal of Pharmaceutical Education 2019; 83 (2) Article 6867.}

of these limitations, the objective of our study was to evaluate a multi-institutional dataset of pharmacy students' PCOA and NAPLEX total and content area scores in order to determine the relationship between the two examinations. Our central hypothesis was that, based on prior research, PCOA scores would be significantly correlated with NAPLEX scores.

\section{METHODS}

To investigate the central hypothesis, we sought to determine the strength of the relationships between the total and content area PCOA scores with the total and content area scores of the NAPLEX; and to determine the significance of total and content area PCOA scores in predicting the total scores on the NAPLEX, controlling for the S/COP attended by the student and cohort year.

The S/COPs in this study shared the commonalities of being public, research-intensive universities whose PharmD programs were traditional, four-year courses of study consisting of three years of didactic courses and one year of advanced pharmacy practice experiences (APPEs). The students included in the sample were those who had been enrolled at the investigators' S/COPs and completed both the PCOA as third-year (P3) pharmacy students (pre-APPE) between 2012 and 2014 and the NAPLEX between 2013 and 2015. With the exception of one program in $2014(\mathrm{n}=95)$, the programs studied used the PCOA only in the P3 year and prior to beginning their APPEs. The NAPLEX scores used in the study were taken from each student's first attempt on the examination. A total of six S/COPs were represented in the dataset, leading to a student sample size of 1,463 cases.

In order to generate a complete, independently matched, and de-identified dataset, the investigators requested data from NABP. Each investigator and program that contributed data completed a data release agreement for NABP. Upon receiving the agreements, NABP linked student PCOA and NAPLEX scores and removed all identifying student information other than the name of the institution, and then provided the data to the principal investigator. The study was granted exempted approval by the Marshall University Office of Research Integrity.

Data analysis was completed to first prepare the descriptive statistics for each variable in the dataset. Next, bivariate correlations (Pearson correlation) were estimated for the total and each PCOA content area score with the total and content area scores of the NAPLEX. The correlation between total PCOA and total NAPLEX score was also examined based on which of five score "bands" each student's NAPLEX score was located within. The bottom band included scores below 75 (examination failure), the three subsequent bands each covered a score range of 15 points, and the top band covered students who scored above 120). A series of regression models then were estimated to predict students' NAPLEX total scores. The total and content area PCOA scores as well as institutional control variables were regressed on the dependent variable. Institutional control variables consisted of dummy variables for students' graduation year and S/COP attended. The S/COP with the most years of data and largest sample was chosen as the reference institution, allowing comparison of the five other S/COPs to the reference. Students in the 2013 cohort were selected as the reference group for the graduation year dummy variables. All analyses were conducted using IBM SPSS 23 (IBM, Armonk, NY).

\section{RESULTS}

The initial dataset consisted of 1,463 students who completed the PCOA as P3 students between 2012 and 2014 at one of the six S/COPs participating in the study. An initial scan of the dataset showed that six students had taken the NAPLEX for the first time after the new examination blueprint was implemented in November 2015. An additional three students did not have any NAPLEX scores. These nine students were removed from the dataset, resulting in a final sample of 1,454 students. Descriptive statistics for the P3 PCOA scores and NAPLEX scores are shown in Table 1 for all students in our sample by cohort year. The mean (SD) total PCOA score was 372 (50) for the 2013 cohort, 388 (47) for the 2014 cohort, and 369 (47) for the 2015 cohort. As a comparison, the national mean PCOA total score for P3 students was 351 (56) for the 2013 cohort, 360 (63) for the 2014 cohort, and 362 (58) for the 2015, suggesting that, on average, students in our sample performed at a somewhat higher level than the overall national sample. ${ }^{4}$ The results of a student $t$-test indicate that the difference between the study sample and national sample was significant for $2013[t(2,105)=5.99, p<.001], 2014[t(2,524)=$ $9.30, p<.001)]$, and $2015[t(2,710)=2.63, p=.01]$. The lower section of Table 1 reports descriptive statistics for the total and content area scores of the NAPLEX for the first attempt of students in our dataset. The mean (SD) NAPLEX total scores for our sample were 104 (13), 106 (13), and 102 (15) for 2013, 2014, and 2015, respectively. Like the PCOA, our mean NAPLEX total scores were slightly higher than the scaled NAPLEX scores for ACPE-accredited schools those years [101 (16), 100 (16), 98 (18)] according to NABP (M. Garrity, PharmD, written communication, October 2017). Among the 1,454 students in our dataset, $42(3 \%)$ did not pass the NAPLEX on the first attempt (ie, they had a total scaled score of less than 75). 
American Journal of Pharmaceutical Education 2019; 83 (2) Article 6867.

Table 1. PCOA Scores and NAPLEX Scores of Third-Year Pharmacy Students by Domain and Cohort

\begin{tabular}{lcccc}
\hline & \multicolumn{3}{c}{ Cohort Year } \\
\cline { 2 - 5 } & $\mathbf{2 0 1 3}(\mathbf{n = 2 9 4 )}$ & $\mathbf{2 0 1 4}(\mathbf{n}=\mathbf{5 1 9})$ & $\mathbf{2 0 1 5}(\mathbf{n}=\mathbf{6 4 1})$ & All Years (n=1454) \\
\hline PCOA & $356.3(77.0)$ & $371.8(73.4)$ & $354.9(75.0)$ & $361.2(75.2)$ \\
BBS Score $^{\mathrm{a}}$ & $361.8(51.0)$ & $387.0(54.5)$ & $366.5(51.4)$ & $372.9(53.5)$ \\
PS Score $^{\mathrm{b}}$ & $367.7(64.1)$ & $386.5(60.3)$ & $378.9(70.2)$ & $379.4(65.8)$ \\
SBS Score $^{\mathrm{c}}$ & $403.2(69.3)$ & $404.4(59.6)$ & $379.9(55.5)$ & $393.4(61.1)$ \\
CS Score $^{\mathrm{d}}$ & $765.0(110.5)$ & $791.5(101.8)$ & $746.4(95.7)$ & $766.2(102.9)$ \\
PS-CS Score & $371.8(50.3)$ & $387.5(46.8)$ & $368.6(47.0)$ & $376.0(48.4)$ \\
Total Score & & & & $12.5(1.1)$ \\
& & & & $12.7(1.2)$ \\
NAPLEX $_{\text {Area 1 Score }}^{\mathrm{f}}$ & $12.6(1.0)$ & $12.6(1.1)$ & $12.5(1.1)$ & $12.9(1.7)^{\mathrm{i}}$ \\
Area 2 Score & $12.5(1.2)$ & $12.9(1.2)$ & $12.7(1.8)^{\mathrm{i}}$ & $103.8(13.8)$ \\
Area 3 Score & $12.9(1.5)$ & $13.0(1.6)$ & $102.4(14.5)$ & \\
Total Score & $103.6(13.0)$ & $105.5(13.1)$ &
\end{tabular}

Abbreviations: Pharmacy Curriculum Outcomes Assessment (PCOA); North American Pharmacist Licensure Exam (NAPLEX)

${ }^{\text {a }}$ Basic biomedical sciences

b Pharmaceutical sciences

${ }^{c}$ Social, behavioral, and administrative sciences

${ }^{\mathrm{d}}$ Clinical sciences

${ }^{\mathrm{e}}$ Combined basic biomedical sciences and clinical sciences score

${ }^{\mathrm{f}}$ Area 1: Assess pharmacotherapy to assure safe and effective therapeutic outcomes

${ }^{\mathrm{g}}$ Area 2: Assess safe and accurate preparation and dispensing of medications

${ }^{\mathrm{h}}$ Area 3: Assess, recommend, and provide health care information that promotes public health

${ }^{\mathrm{i}}$ Six students did not have an area 3 score in 2015

Table 2 presents the correlations between students' total and content area scores on the PCOA and NAPLEX. All correlations between the PCOA and NAPLEX were found to be significant at an alpha level of $p \leq .001$. Total PCOA scores and total NAPLEX scores were moderately correlated, $r=0.54 .{ }^{14}$ Correlations between the individual content areas of the PCOA and NAPLEX total score were moderate, with the strongest relationship occurring between NAPLEX total score and a combined measure for the pharmaceutical sciences and clinical sciences areas (PS-CS), $r=0.56$, followed by the individual scores for pharmaceutical sciences (PS), $r=0.51$, and clinical sciences (CS), $r=0.50$. The correlation between students' P3 PCOA total scores and NAPLEX total scores was also examined based on which of five score bands each student's NAPLEX score was located within. The results from these correlations are reported in Table 3. Total PCOA scores and total NAPLEX scores were significantly correlated for each of the student groups $(p \leq .05)$. The strongest correlations were observed for students who failed to attain a total scaled score of 75 on the NAPLEX $(r=0.43)$ and those who scored in the highest band on the NAPLEX $(r=0.33)$.

The results of a simple linear regression model using PCOA total score to predict NAPLEX total score are located in column one of Table 4 (Model 1). This initial model was expanded to include dummy variables for the different schools in the sample (Model 2) and for the different student cohort years (Model 3). Model 2 was determined to be the final, parsimonious model when using PCOA total score as the primary independent variable and was consequently used to interpret the results. In each of these first three models, the coefficient for total PCOA score was significant. From Model 2, we estimated that a 1-point increase in a student's P3 PCOA score is associated with a 0.15 -point increase in NAPLEX total score, controlling for other factors. When interpreted at the mean PCOA total score (376.0), the estimated NAPLEX total score is predicted to be 101.4. Each of the dummy variables for schools 1-4 was significant and positive, whereas neither of the dummy variables for cohort year was significant (Model 3). Finally, $\mathrm{R}^{2}$ for Model 2 suggests that approximately $31 \%$ of the variance in NAPLEX total scores was accounted for by the independent variables.

The results from several multiple linear regression models using PCOA content scores to predict NAPLEX total score are presented in columns 4-8 of Table 4. Results for the simplest model, with only the four PCOA content area scores used as predictors, are reported in column 4 (Model 4). In Model 5, the BBS and SBS content area scores were retained as independent variables; however, the individual PS and CS scores were replaced 


\section{American Journal of Pharmaceutical Education 2019; 83 (2) Article 6867.}

Table 2. Bivariate Correlation Estimates for PCOA and NAPLEX Total and Content Area Scores of Third-Year Pharmacy Students

\begin{tabular}{|c|c|c|c|c|c|c|c|c|c|c|}
\hline & $\begin{array}{c}\text { PCOA } \\
\text { Total } \\
\end{array}$ & $\begin{array}{c}\text { PCOA } \\
\text { BBS }^{\mathbf{a}} \\
\end{array}$ & $\begin{array}{c}\text { PCOA } \\
\text { PS }^{\mathbf{b}}\end{array}$ & $\begin{array}{c}\text { PCOA } \\
\text { SBS }^{\mathbf{c}} \\
\end{array}$ & $\begin{array}{c}\text { PCOA } \\
\text { CS }^{\mathrm{d}}\end{array}$ & $\begin{array}{l}\text { PCOA } \\
\text { PS-CS }\end{array}$ & $\begin{array}{c}\text { NAPLEX } \\
\text { Total } \\
\end{array}$ & $\begin{array}{c}\text { NAPLEX } \\
\text { Area } \mathbf{f}^{\mathrm{f}} \\
\end{array}$ & $\begin{array}{c}\text { NAPLEX } \\
\text { Area } 2^{\mathrm{g}} \\
\end{array}$ & $\begin{array}{c}\text { NAPLEX } \\
\text { Area } 3^{\mathrm{h}} \\
\end{array}$ \\
\hline $\begin{array}{l}\text { PCOA } \\
\text { Total }\end{array}$ & 1.00 & & & & & & & & & \\
\hline $\begin{array}{l}\text { PCOA } \\
\text { BBS }^{\text {a }}\end{array}$ & .75 & 1.00 & & & & & & & & \\
\hline PCOA PS ${ }^{\mathrm{b}}$ & .87 & .60 & 1.00 & & & & & & & \\
\hline $\begin{array}{l}\text { PCOA } \\
\text { SBS }^{\mathrm{c}}\end{array}$ & .70 & .35 & .48 & 1.00 & & & & & & \\
\hline PCOA CS ${ }^{\mathrm{d}}$ & .86 & .54 & .61 & .53 & 1.00 & & & & & \\
\hline $\begin{array}{l}\text { PCOA } \\
\text { PS-CS }\end{array}$ & .96 & .63 & .88 & .56 & .91 & 1.00 & & & & \\
\hline $\begin{array}{c}\text { NAPLEX } \\
\text { Total }\end{array}$ & .54 & .37 & .51 & .32 & .50 & .56 & 1.00 & & & \\
\hline $\begin{array}{l}\text { NAPLEX } \\
\text { Area } 1^{\mathrm{f}}\end{array}$ & .47 & .34 & .44 & .25 & .44 & .49 & .89 & 1.00 & & \\
\hline $\begin{array}{l}\text { NAPLEX } \\
\text { Area } 2^{\mathrm{g}}\end{array}$ & .46 & .27 & .45 & .33 & .39 & .46 & .78 & .55 & 1.00 & \\
\hline $\begin{array}{c}\text { NAPLEX } \\
\text { Area } 3^{\mathrm{h}}\end{array}$ & .34 & .22 & .29 & .22 & .33 & .35 & .50 & .37 & .35 & 1.00 \\
\hline
\end{tabular}

Abbreviations: Pharmacy Curriculum Outcomes Assessment (PCOA); North American Pharmacist Licensure Exam (NAPLEX)

All correlations are statistically significant at a level of $p \leq .001$

${ }^{a}$ Basic biomedical sciences

${ }^{\mathrm{b}}$ Pharmaceutical sciences

${ }^{\mathrm{c}}$ Social, behavioral, and administrative sciences

${ }^{\mathrm{d}}$ Clinical sciences

${ }^{\mathrm{e}}$ Combined basic biomedical sciences and clinical sciences score

${ }^{\mathrm{f}}$ Area 1: Assess pharmacotherapy to assure safe and effective therapeutic outcomes

${ }^{g}$ Area 2: Assess safe and accurate preparation and dispensing of medications

${ }^{\mathrm{h}}$ Area 3: Assess, recommend, and provide health care information that promotes public health

with a combined measure for these two areas, PS-CS. Model 5 was re-estimated to include dummy variables for school (Model 6) and cohort (Model 7). Results from a final parsimonious model using the significant predictors from Models 6-7 are reported in the final column of Table 4 (Model 8). The content area scores for BBS and SBS were not significant in each of the models, whereas PS and CS were significant in Model 4 and the combined measure of these two scores was significant in Models 5-8. Consistent with the results from the earlier models using PCOA total score, neither year dummy variable was significant. From Model 8, a 1-point increase in students' combined PS-CS score on the PCOA is associated with 0.07 -point increase in total NAPLEX score, controlling for other factors. The $R^{2}$ value for the final, parsimonious model (Model 8) indicates that approximately $33 \%$ of the variance in total NAPLEX score has been accounted for by the model.

\section{DISCUSSION}

This study examined the relationship between student performance on the PCOA and NAPLEX using a

Table 3. Bivariate Correlation Estimates for PCOA Total Scores and NAPLEX Total Scale Scores by NAPLEX Score Interval for Third-Year Pharmacy Students

\begin{tabular}{|c|c|c|c|}
\hline NAPLEX Scale Score Interval & No. (\% of sample) & $r$ & $p$ value \\
\hline$<75$ & $42(2.9)$ & 0.43 & $<.01$ \\
\hline $75 \leq \mathrm{x}<90$ & $186(12.8)$ & 0.18 & .02 \\
\hline $105 \leq \mathrm{x}<120$ & $621(42.7)$ & 0.26 & $<.001$ \\
\hline $120 \leq \mathrm{x}$ & $155(10.7)$ & 0.33 & $<.001$ \\
\hline
\end{tabular}

Abbreviations: Pharmacy Curriculum Outcomes Assessment (PCOA); North American Pharmacist Licensure Exam (NAPLEX) 


\section{American Journal of Pharmaceutical Education 2019; 83 (2) Article 6867.}

Table 4. Unstandardized Estimates for Linear Regression Analyses Using PCOA Total and Content Scores to Predict NAPLEX Total Score

\begin{tabular}{|c|c|c|c|c|c|c|c|c|}
\hline & $\begin{array}{c}\text { Model } 1 \\
\text { b (SE) }\end{array}$ & $\begin{array}{c}\text { Model 2d }^{\mathrm{d}} \\
\text { b (SE) }\end{array}$ & $\begin{array}{c}\text { Model } 3 \\
\text { b (SE) }\end{array}$ & $\begin{array}{c}\text { Model } 4 \\
\text { b }(\mathrm{SE})\end{array}$ & $\begin{array}{c}\text { Model } 5 \\
\text { b (SE) }\end{array}$ & $\begin{array}{c}\text { Model } 6 \\
\text { b }(\mathrm{SE})\end{array}$ & $\begin{array}{c}\text { Model } 7 \\
\text { b (SE) }\end{array}$ & $\begin{array}{c}\text { Model 8 } \\
\text { b (SE) }\end{array}$ \\
\hline$\overline{\text { Intercept }}$ & $45.46(2.38)^{\mathrm{c}}$ & $44.26(2.42)^{\mathrm{c}}$ & $45.97(2.46)^{\mathrm{c}}$ & $45.76(2.34)^{\mathrm{c}}$ & $46.16(2.32)^{\mathrm{c}}$ & $45.64(2.35)^{\mathrm{c}}$ & $45.97(2.42)^{\mathrm{c}}$ & $\overline{45.71(2.28)^{\mathrm{c}}}$ \\
\hline $\begin{array}{l}\text { PCOA } \\
\text { Total }\end{array}$ & $0.16(0.01)^{\mathrm{c}}$ & $0.15(0.01)^{\mathrm{c}}$ & $0.16(0.01)^{\mathrm{c}}$ & & & & & \\
\hline $\begin{array}{l}\text { PCOA } \\
\text { BBS }^{f}\end{array}$ & & & & $0.00(0.00)$ & $0.00(0.00)$ & $0.01(0.01)$ & $0.00(0.00)$ & \\
\hline PCOA PS ${ }^{g}$ & & & & $0.08(0.01)^{\mathrm{c}}$ & & & & \\
\hline $\begin{array}{l}\text { PCOA } \\
\text { SBS }^{h}\end{array}$ & & & & $0.00(0.01)$ & $0.00(0.01)$ & $0.00(0.01)$ & $0.00(0.01)$ & \\
\hline PCOA CS ${ }^{\mathrm{i}}$ & & & & $0.07(0.01)^{\mathrm{c}}$ & & & & \\
\hline $\begin{array}{l}\text { PCOA } \\
\quad \text { PS-CS }\end{array}$ & & & & & $0.07(0.00)^{\mathrm{c}}$ & $0.07(0.00)^{\mathrm{c}}$ & $0.07(0.00)^{\mathrm{c}}$ & $0.07(0.00)^{\mathrm{c}}$ \\
\hline $\begin{array}{l}\text { School } 1 \\
\text { dummy }\end{array}$ & & $2.95(0.95)^{\mathrm{b}}$ & & & & $2.79(0.97)^{\mathrm{b}}$ & & $2.38(0.94)^{b}$ \\
\hline $\begin{array}{l}\text { School } 2 \\
\text { dummy }\end{array}$ & & $4.42(0.89)^{\mathrm{c}}$ & & & & $4.11(0.95)^{\mathrm{c}}$ & & $3.53(0.89)^{\mathrm{c}}$ \\
\hline $\begin{array}{l}\text { School } 3 \\
\text { dummy }\end{array}$ & & $3.80(0.99)^{\mathrm{c}}$ & & & & $4.30(0.98)^{\mathrm{c}}$ & & $4.35(0.98)^{\mathrm{c}}$ \\
\hline $\begin{array}{l}\text { School } 4 \\
\text { dummy }\end{array}$ & & $2.30(0.94)^{\mathrm{a}}$ & & & & $1.92(0.95)^{\mathrm{a}}$ & & $1.52(0.92)$ \\
\hline $\begin{array}{l}\text { School } 5 \\
\text { dummy }\end{array}$ & & $1.16(1.32)$ & & & & $1.51(1.30)$ & & $1.36(1.30)$ \\
\hline $\begin{array}{l}2014 \text { cohort } \\
\text { dummy }\end{array}$ & & & $-0.48(0.85)$ & & & & $-0.05(0.84)$ & \\
\hline $\begin{array}{c}2015 \text { cohort } \\
\text { dummy }\end{array}$ & & & $-0.67(0.82)$ & & & & $0.18(0.81)$ & \\
\hline $\mathrm{R}^{2}$ & 0.30 & 0.31 & 0.30 & 0.32 & 0.31 & 0.33 & 0.31 & 0.33 \\
\hline $\begin{array}{l}\text { Abbreviation } \\
{ }^{\mathrm{a}} p \leq .05 \\
{ }^{\mathrm{b}} p \leq .01 \\
{ }^{\mathrm{c}} p \leq .001 \\
{ }^{\mathrm{d}} \text { Final model } \\
{ }^{\mathrm{e}} \text { Final model } \\
{ }^{\mathrm{f}} \text { Basic biome } \\
{ }^{\mathrm{g}} \text { Pharmaceut } \\
{ }^{\mathrm{g}} \text { Social, beh } \\
{ }^{\mathrm{i}} \text { Clinical scie }\end{array}$ & $\begin{array}{l}\text { Pharmacy Cur } \\
\text { containing PCO } \\
\text { containing PCO } \\
\text { dical sciences } \\
\text { ical Sciences } \\
\text { ivioral, and adm } \\
\text { nces }\end{array}$ & $\begin{array}{l}\text { riculum Outcom } \\
\text { A Total Score a } \\
\text { A sub-content s } \\
\text { nistrative scienc }\end{array}$ & $\begin{array}{l}\text { es Assessment (I } \\
\text { s primary indepe } \\
\text { cores as primary }\end{array}$ & $\begin{array}{l}\text { endent variable u } \\
\text { independent var }\end{array}$ & $\begin{array}{l}\text { Ised to interpr } \\
\text { riables used to }\end{array}$ & $\begin{array}{l}\text { egression coe } \\
\text { erpret regress }\end{array}$ & $\begin{array}{l}\text { cients } \\
\text { n coefficients }\end{array}$ & \\
\hline
\end{tabular}

large dataset consisting of more than 1,400 students from six S/COPs. As such, this study addresses several important limitations identified in a recent review article of best practices for PCOA research, which noted the prevalence of single-institution datasets and small sample sizes in existing studies. ${ }^{13}$ Overall, our findings were largely consistent with previously published research. Our estimate for the total PCOA score and total NAPLEX score correlation of $r=0.54$ is similar to other published estimates $(r=0.56$ to $r=0.73) .^{9-11,14}$ Our correlation estimates for the individual PCOA area scores with the NAPLEX area scores were similar to those of Naughton et al. However, we determined the relationships to be somewhat weaker, in general, than those identified in their study. ${ }^{11}$

An area examined in the current study that had not been previously evaluated is the relationship between students' scores on NAPLEX and the PCOA based on "score band" on the NAPLEX. The strongest correlation between PCOA total score and NAPLEX total score was observed for students who failed to attain a total scaled score of 75 on the NAPLEX, followed by top performing students who scored at or above 120, which suggests that students' PCOA and NAPLEX scores were most closely coupled for the highest and lowest performers. 


\section{American Journal of Pharmaceutical Education 2019; 83 (2) Article 6867.}

The regression models we used to predict NAPLEX total score, although more robust, yielded similar results to previous research. Previous studies did not report the regression coefficients, which provide important insight into the nature of the relationships between the two examinations. We estimated that a 1-point increase in PCOA total score was associated with a 0.15 -point increase in NAPLEX total score, and a 1-point increase in the combined measure for the pharmaceutical sciencesclinical sciences subscores was estimated to increase a student's NAPLEX total score by an average of 0.07 points. We also determined that between $30 \%$ and $33 \%$ of the variance in NAPLEX total score could be accounted for using PCOA total or content area scores, which is consistent with findings by Sousa (33\%), Garavalia and colleagues (31\%), and Ferrence and Welch (33\%-45\%). ${ }^{10,14,15}$

The fact that PCOA accounted for only about onethird of the variance in student NAPLEX performance may in part be attributable to differences between the examination blueprints. PCOA was not developed as a predictor of NAPLEX performance but rather as an external assessment of student performance in pharmacy curricula. ${ }^{1}$ Possibly, student intrinsic motivation may have differed and consequently confounded the relationship between the PCOA and NAPLEX. Additionally, the modest $R^{2}$ values suggest the possibility of other factors associated with NAPLEX performance that were not included in our models. As an example, Garavalia et al were able to account for a slightly greater proportion of the variance (39\%) by including students' cumulative didactic GPAs along with PCOA scores in their models for NAPLEX total score. ${ }^{14}$ Other studies have identified student admissions variables (PCAT, prepharmacy grade point average, age), pre-NAPLEX scores, and having no course failures as being significant predictors of NAPLEX score. ${ }^{16-18}$ It is important for future studies to incorporate additional measures of student academic success to obtain a more accurate prediction of NAPLEX outcomes and limit the possibility of omitted variable bias. As evidence continues to be generated, S/COPs could implement a holistic approach to support the development of individualized student remediation plans. Such strategies may rely upon time-adaptive predictive models to identify students most at risk for NAPLEX failure and targeted remediation based on low-scoring areas from various assessments shown to correlate with the NAPLEX. Assessments are likely to differ by S/COP, but may include course grades or failures, PCOA, practicums and clinical examinations, and experiential assessments.

Our study had a number of strengths due in part to the nature of the sample. We examined 3 years of data from multiple public institutions representing various regions of the country. By comparison, previously published studies have used data from a single institution, thereby limiting the generalizability of their results. Further, we received de-identified, matched data directly from NABP that included all students from the study institutions who completed both the PCOA and the NAPLEX during the years of interest; prior research has relied upon data that were released to the school by obtaining individual student agreements. Lastly, another potential strength (but also a limitation) is that the dataset is fairly homogenous because it consists exclusively of public, research-intensive universities with traditional four-year courses of study. However, this means that that sample is not representative of all S/COPs, as evidenced by the mean PCOA and NAPLEX scores, which were somewhat higher than the national means.

There were a few other specific limitations of the study. First, we were unable to obtain student demographic and other background variables to include in the models. This information would likely have improved model fit and allowed us to control for other factors that may confound the relationship between the PCOA and NAPLEX. Second, during the time period from which data were compiled, S/COPs had the option to administer the test via computer or pen and paper, and we learned that both methods had been used by the different S/COPs in our dataset. Third, the S/COPs included in the study reported attaching various stakes throughout the study period to students' performance on the PCOA. Because five of the six S/COPs administered the exam as low- or nostakes examinations in all years, student effort may represent still another confounding factor that could not be addressed within the analyses. Lastly, the nature of the relationship between the PCOA and NAPLEX may have changed since 2016 because of changes in the blueprints of both examinations as well as the length and format of the NAPLEX.,3

Multiple factors should be considered as we look at the future utility of PCOA and its impact on NAPLEX performance. As noted above, there have been changes to both the PCOA and the NAPLEX since the data for this study were collected. New NAPLEX competencies were implemented in November of 2015, and the NAPLEX is now administered as a computer non-adaptive examination. ${ }^{3}$ The PCOA competencies were updated for the 2016-2017 testing windows. ${ }^{2}$ Additionally, the implementation of the new 2016 ACPE Standards require the use of the PCOA for students prior to their APPEs and $\mathrm{S} / \mathrm{COPs}$ are expected to have assessments in place to "ensure that graduating students are practice-ready and teamready." "Thus, more S/COPs are using the PCOA than in 


\section{American Journal of Pharmaceutical Education 2019; 83 (2) Article 6867.}

the past, and many have or are considering using the examination as high stakes. ${ }^{19}$ Future studies should look to determine the impact of these changes on the correlation of PCOA and NAPLEX scores.

\section{CONCLUSION}

Consistent with previously published research, the student PCOA and NAPLEX total and content area scores that we compared in this study were significantly correlated. The relatively modest amount of variance in NAPLEX accounted for by PCOA within our models illustrates the need for S/COPs to consider additional measures of performance when evaluating preparedness for the NAPLEX. Because of our use of a large multi-year dataset from multiple $\mathrm{S} / \mathrm{COPs}$, our study provides important baseline data that can be used by S/COPs for comparison with their own student data from this time period. Moreover, our results may be useful to researchers seeking to conduct additional analyses following the recent changes in PCOA and NAPLEX blueprints. Although we compiled data from multiple schools and colleges for this study, each of the schools and colleges was affiliated with a large, public, research-intensive university. Consequently, schools and colleges are encouraged to exercise sound judgment when interpreting their results within the context of our findings.

\section{ACKNOWLEDGMENTS}

We would like to thank Maria Incrocci, RPh, MS, for her early assistance with this project, and the staff at the National Association Boards of Pharmacy for their review.

\section{REFERENCES}

1. National Association Boards of Pharmacy. Pharmacy Curriculum Outcomes Assessment. 2017; https://nabp.pharmacy/programs/pcoa/. Accessed July 31, 2017.

2. National Association Boards of Pharmacy. The 2015 United States Schools and Colleges Curriculum Survey. https://nabp.pharmacy/wpcontent/uploads/2016/09/2015-US-Pharmacy-Curricular-SurveySummary-Report.pdf. Accessed October 27, 2017.

3. National Association Boards of Pharmacy. NAPLEX and MJPE 2019 Candidate Registration Bulletin 2019. https://nabp.pharmacy/ wp-content/uploads/2019/03/NAPLEX-MPJE-Bulletin-March-2019. pdf. Accessed March 13, 2019.

4. National Association Boards of Pharmacy. 2014-2017 PCOA administration highlights. https://nabp.pharmacy/wp-content/
uploads/2018/03/PCOA-Highlights-2018.pdf. Accessed March 13, 2019.

5. Gortney JS, Bray BS, Salinitri FD. Implementation and use of the pharmacy curriculum outcomes assessment at US schools of pharmacy. Am J Pharm Educ.2015;79(9):Article 137.

6. Accreditation Council for Pharmacy Education. Accreditation standards and guidelines for the professional program in pharmacy leading to the doctor of pharmacy degree. Standards 2016. https:// www.acpe-accredit.org/pdf/Standards2016FINAL.pdf. Accessed February 29, 2016.

7. Accreditation Council for Pharmacy Education. Guidance for the accreditation standards and key elements for the professional program in pharmacy leading to the doctor of pharmacy degree. 2016; https://www.acpeaccredit.org/pdf/GuidanceforStandards2016 FINAL.pdf. Accessed September 26, 2017.

8. Accreditation Council for Pharmacy Education. Self-assessment instrument for the professional degree program of colleges and schools of pharmacy 2016; https://www.acpe-accredit.org/pdf/ Rubric2016Guidelines1.0b.pdf. Accessed September 26, 2017. 9. Buring SM, Hein BE, Messinger NJ, Wigle PR. The PCOA effect: the Cincinnati experience. Am J Pharm Educ. 2015;79(5):Article 122. 10. Sousa JM, Hutchinson DJ, Lenhard LM. Pharmacy Curriculum Outcomes Assessment (PCOA) as predictors of performance on NAPLEX. Am J Pharm Educ. 2015;79(5):Article 4.

11. Naughton C, Friesner DL. Correlation of P3 PCOA scores with future NAPLEX scores. Curr Pharm Teach Learn. 2014;6(6):877883.

12. Portney LG, Watkins MP. Foundations of Clinical Research Applications to Practice. Upper Saddle River, NJ: Pearson Education, Inc.; 2009.

13. Mok TY, Romanelli F. Identifying best practices for and utilities of the Pharmacy Curriculum Outcome Assessment Examination. Am $J$ Pharm Educ. 2016;80(10):Article 163.

14. Garavalia LS, Prabhu S, Chung E, Robinson DC. An analysis of the use of Pharmacy Curriculum Outcomes Assessment (PCOA) scores within one professional program. Curr Pharm Teach Learn. 2017;9(2):178-184.

15. Ferrence JD, Welch AC. Using PCOA: experiences from two early adopter schools. Am J Pharm Ed. 2017;81(5):Article 9. 16. Allen RE, Diaz C, Jr. Use of preadmission criteria and performance in the doctor of pharmacy program to predict success on the North American Pharmacists Licensure Examination. Am J Pharm Educ.2013;77(9):Article 193.

17. McCall KL, MacLaughlin EJ, Fike DS, Ruiz B. Preadmission predictors of PharmD graduates' performance on the NAPLEX. Am J Pharm Educ. 2007;71(1):Article 5.

18. Chisholm-Burns MA, Spivey CA, Byrd DC, McDonough SLK, Phelps SJ. Examining the association between the NAPLEX, preNAPLEX, and pre- and post-admission factors. Am J Pharm Educ. 2017;81(5):Article 86.

19. Gortney JS, Rudolph M, Augustine JA, et al. Pharmacy Curriculum Outcomes Assessment use for remediation across the academy: results of a national survey. Am J Pharm Educ. 2017;81(5): Article S6. 